\title{
The effect of forage type on lamb carcass traits, meat quality and sensory traits
}

\author{
Gerlane F. De Brito a,c,*, Shawn R. McGrath ${ }^{\text {b,e }}$, Benjamin W.B. Holman ${ }^{\text {c }}$, Michael A. Friend ${ }^{\text {b,e }}$, \\ Stephanie M. Fowler ${ }^{\text {c,e }}$, Remy J. van de Ven ${ }^{d}$, David L. Hopkins ${ }^{c, e}$

\footnotetext{
${ }^{a}$ Faculty of Veterinary and Agricultural Sciences, São Paulo State University, Via de Acesso Prof. Paulo Donato Castelane, s/n - Vila Industrial, 14884-900 Jaboticabal, Brazil

b School of Animal and Veterinary Science, Charles Sturt University, Wagga Wagga, NSW 2650, Australia

c Centre for Red Meat and Sheep Development, NSW Department of Primary Industries, Cowra, NSW 2794, Australia

d Orange Agricultural Institute, NSW Department of Primary Industries, Orange, NSW 2800, Australia

e Graham Centre for Agricultural Innovation, Pugsley Place, Wagga Wagga, NSW 2650, Australia
}

\section{A R T I C L E I N F O}

\section{Article history:}

Received 20 January 2016

Received in revised form 21 March 2016

Accepted 22 April 2016

Available online 23 April 2016

\section{Keywords:}

Chicory

Grazing forages

Bladder

Colour

Glycogen

Brassica

Dressing percentage

\begin{abstract}
A B S T R A C T
The aim of this study was to evaluate the effect of different forage-types on lamb carcass, meat quality and sensory attributes. Sixty-two, White Dorper lambs finished on bladder clover, brassica, chicory + arrowleaf clover, lucerne + phalaris or lucerne, were slaughtered at a commercial abattoir. At $24 \mathrm{~h}$ post-mortem, the m. longissimus thoracis et lumborum (LL) was removed from the left side and sliced into three equal sub-samples, vacuum packaged and randomly assigned to ageing periods ( 5,12 or 40 days) and the right side was aged for 5 days. The $m$. semimembranosus and $m$. adductor femoris were removed and, the former was then aged for 40 days. Lambs fed chicory + arrowleaf clover or lucerne had a higher dressing percentage and fat depth. Bladder clover gave the highest level of glycogen in the LL. No sensory or other meat quality trait differences were found between the treatments. In general, no treatments showed any unfavourable effect on the traits examined.
\end{abstract}

Crown Copyright $@ 2016$ Published by Elsevier Ltd. All rights reserved.

\section{Introduction}

Red meat in general is considered a contributor of important nutrients in the diet of humans and a valuable source of dietary protein and iron (Ponnampalam et al., 2010). Lamb diet is one of the main environmental factors which affect carcass and meat quality (Fraser \& Rowarth, 1996). Diet has been shown to influence the fatty acid profiles, antioxidant properties, rate of protein synthesis, colour, flavour, tenderness and others properties of meat quality (Young, Cruickshank, MacLean, \& Muir, 1994; Wood et al., 2004; Kim, Stuart, Rosenvold, \& Maclennan, 2013). These effects are important as the central objective of animal industries is to produce high quality meat that meets consumer demands and expectations (Jiang et al., 2015).

Australian lamb producers often use extensive forage-based finishing systems that include irrigated, dryland, green and senesced pasture, as well as feed supplements (Ponnampalam et al., 2014). When compared with concentrate-based systems the forage-based systems are better suited to finishing lambs because of: a lower fat content (Blackburn, Snowder, \& Glimp, 1991); reduced production costs

\footnotetext{
* Corresponding author at: 296 Binni Creek Road, (PO BOX 129), Cowra, NSW 2794, Australia.

E-mail address: gerlaneferreira@zootecnista.com.br (G.F. De Brito).
}

(Woodward \& Fernández, 1999); better use of natural resources; and provision of meat quality that better represents consumer requirements (Grunert, Bredahl, \& Brunsø, 2004). However, seasonal oscillations and climatic variability can affect forage quantity, nutritional quality and availability and as consequence, affect lambs capacity to achieve their productivity potential (Nardone, Ronchi, Lacetera, Ranieri, \& Bernabucci, 2010) by exhibiting slower growth rates, lower carcass weights and potentially meat with a lower nutritional value (Winichayakul et al., 2008) compared to concentrate finished animals.

Efficient forage-types must have high protein and low cellulose and hemicellulose content (Fraser \& Rowarth, 1996). Novel forage types offer a way to fulfil this prerequisite (Brown, 1990; Howes, Bekhit, Burritt, \& Campbell, 2015), but some forage-types may alter carcass and meat quality. Thus, identifying novel forage-types that improve lamb production and meat quality simultaneously is advantageous (Aurousseau et al., 2007). A number of previous studies which have evaluated different forage-types have attempted to address these requirements, but their value has been limited by the forage-types studied and fundamental experimental design flaws, for instance failing to sufficiently replicate treatments (e.g. Hopkins, Beattie, \& Pirlot, 1995a; Hopkins, Holst, Hall, \& Atkinson, 1995b). Despite these limitations there are indications that if for example lambs are finished on brasscias that this can lower sensory quality (Hopkins et al., 1995a) and there 
reports of off-flavours developing Park, Spurway, Wheeler (1972). The contention was that some novel forage types may have a detrimental effect on various meat quality traits including sensory traits. Therefore the aim of this study was, to evaluate the effect of three novel forage types (Bladder clover, Brassica, Chicory + Arrowleaf clover) in comparison to more common forages (Lucerne + Phalaris and Lucerne) on the lamb carcass, meat and eating quality traits.

\section{Material and methods}

\subsection{Experimental design}

All animal procedures were approved by the Charles Sturt University Animal Care and Ethics Committee (Protocol No. 12/101). Experimental design and treatments were described by McGrath, Sandral, Friend (2015). Briefly, weaned, mixed-sex (wether and ewe) lambs grazed replicated ( 3 plots per forage-type) pastures sown to bladder clover (Trifolium spumosum cv. Bartolo) $(\mathrm{n}=12)$, hybrid forage brassica (Brassica napus cv. Stego) $(\mathrm{n}=12)$, lucerne (Medicago sativa cv. SARDI 10) $(\mathrm{n}=12)$, chicory (Cichorium intybus cv. Choice) + arrowleaf clover (Trifolium vesiculosum $\mathrm{cv}$. Arrowtas) $(\mathrm{n}=15)$ and lucerne + phalaris (Phalaris aquatica cv. Advanced AT) $(\mathrm{n}=11)$ for 49 days from 15 of October to 2 of December 2014. The lambs were weighed initially $(34.4 \pm 5.6 \mathrm{~kg})$ and then thereafter weekly throughout the field experiment and finally two days prior to slaughter following an overnight curfew $(44.1 \pm 6.4 \mathrm{~kg}$ ) before then being returned to their assigned plots. Pluck samples were collected from pastures to reflect likely diet composition (Cook, 1964), dried at $70{ }^{\circ} \mathrm{C}$ for $48 \mathrm{~h}$ and tested for metabolisable energy (ME) and crude protein (CP) using NIR spectroscopy (Table 1) (CSIRO, 2007).

\subsection{Slaughter}

Only the lambs that had reached to the minimum live weight of $36 \mathrm{~kg}$ were slaughtered and they were then transported to a commercial abattoir ( $400 \mathrm{~km}$ away), where they were held in lairage overnight and slaughtered as a single group the following day. Head only stunning was used prior to slaughter and after slaughter all carcasses were exposed to a number of electrical inputs routinely used by the cooperating abattoir. These included application from a high frequency immobilisation unit, applied for 25-35 s (2000 Hz, $400 \mathrm{~V}$, and a maximum current of 9 A over 7 animals, pulse width of $150 \mu$ s) and moderate frequency immobilisation $(800 \mathrm{~Hz}, 300$ peak volts, a constant current of $1.7 \mathrm{~A}$, pulse width $150 \mu \mathrm{s}$ ) applied for 5-7 s. This was followed by low voltage electronic bleed ( $15 \mathrm{~Hz}, 550$ peak volts, constant current of $0.8 \mathrm{~A}$, pulse width $500 \mu \mathrm{s}$ ) applied for $20 \mathrm{~s}$ and post dressing medium voltage electrical stimulation (MVS) with a constant current $1.0 \mathrm{~A}$ and pulse

Table 1

Metabolisable energy (ME, MJ/kg), crude protein ( $\mathrm{CP}, \mathrm{g} / \mathrm{kg} \mathrm{DM}$ ) and neutral detergent fibre (NDF, $\mathrm{g} / \mathrm{kg} \mathrm{DM}$ ) of five forage types used to graze lambs. Adapted from McGrath et al. (2015).

\begin{tabular}{lrrlll}
\hline Date & Bladder & Brassica & Chicory/arrowleaf & Lucerne/phalaris & Lucerne \\
\hline ME & & & & & \\
October & 11.2 & 11.0 & 12.5 & 9.6 & 12.8 \\
November & 9.2 & 8.4 & 11.5 & 8.0 & 11.7 \\
December & 8.4 & 5.6 & 10.4 & 7.7 & 10.8 \\
CP & & & & & \\
October & 19.1 & 22.5 & 30.5 & 19.0 & 29.0 \\
November & 14.4 & 16.3 & 20.2 & 11.9 & 23.8 \\
December & 16.0 & 10.9 & 16.4 & 18.1 & 22.5 \\
NDF & & & & & \\
October & 37.1 & 17.6 & 34.8 & 48.7 & 33.5 \\
November & 47.8 & 35.6 & 38.4 & 56.4 & 40.8 \\
December & 60.3 & 51.1 & 41.7 & 58.2 & 43.4 \\
\hline
\end{tabular}

$\mathrm{ME}=0.203 \times \mathrm{DOMD}-3.001$ (Packer, Clayton, \& Cusack, 2011). width of $2500 \mu \mathrm{s}$, but variable frequency across the 6 electrodes (the frequency for electrodes 1 \& 2 was set at $25 \mathrm{~Hz}, 3$ \& 4 at $15 \mathrm{~Hz}$ and 5 \& 6 at $10 \mathrm{~Hz}$, with 300 peak volts) applied for 30-35 s as described by Toohey, van de Ven, Thompson, Geesink, Hopkins (2013).

\subsection{Carcass preparation and measurements}

All carcasses were trimmed according to AUS-MEAT specifications (Anonymous, 2005). Hot carcass weight (HCW) was recorded and the depth of tissue at the GR site (the depth of muscle and fat tissue from the surface of the carcass to the lateral surface of the twelfth rib (110$\mathrm{mm}$ from the midline) was measured using a GR knife. The dressing process included the removal of the pelt; evisceration; removal of the skull at the junction of the cervical vertebrae; and removal of the hooves at the carpus/metacarpus and tarsus/metatarsus joints, allowing the carcass to be hung from the Achilles tendon.

\subsection{Sampling}

Sample cores from the right side of the $m$. longissimus thoracis et lumborum ( $\mathrm{LL}$ ) ( $0.5 \mathrm{~cm}$ diameter) were removed from each carcass between the 12th/13th rib upon entry into the chiller (approximately 30 min post-mortem). These were then immediately frozen and transported in liquid nitrogen, then stored in a $-80^{\circ} \mathrm{C}$ freezer prior to analysis for glycogen content. The carcasses remained in the chillers $\left(3-4{ }^{\circ} \mathrm{C}\right.$ ) for $24 \mathrm{~h}$ after which the topside ( $m$. semimembranosus) (Product identification number HAM 5073, Anonymous, 2005) was removed from the right side and the LL was removed from the both sides (Product identification number HAM 4910, Anonymous, 2005). Measures of subcutaneous fat depth (Fat C) and muscle depth and width (EMD and EMW; LL) were taken at the 12th rib by experienced personnel using a metal ruler and these values were multiplied and the product then multiplied by 0.008 as a three component vector to give a cross sectional area estimate (EMA) (Hopkins, Gilbert, Pirlot, \& Roberts, 1992). The fresh colour was measured on the LL at the 12 th rib.

The boned LL and topside were transported (at $4{ }^{\circ} \mathrm{C}$ ) in a portable chiller to the Centre for Red Meat and Sheep Development (NSW Department of Primary Industries, Cowra, New South Wales, Australia). All LL removed from the left side were sliced into three equal samples and vacuum packaged in gas impermeable plastic bags and then randomly assigned to ageing periods of 5,12 or 40 days, so that each LL was represented in each period and used for measurement of water activity and colour under simulated retail display. The other side of LL was aged for 5 days and used to measurement of intramuscular fat, $\mathrm{pH} 24 \mathrm{~h}$, moisture content and sarcomere length and was also used for sensory assessment. Ageing occurred under refrigeration (1.6 ${ }^{\circ} \mathrm{C}$ average). The topside had the $m$. semimembranosus (SM) and $m$. adductor femoris (AF) removed, the cap muscle ( $m$. gracillis) was then removed from the SM. The AF muscle was used to measure moisture content and sample was stored in tubes and freeze-dried for measurement of intramuscular fat (IMF). The SM was vacuum packed, and aged $\left(1.6{ }^{\circ} \mathrm{C}\right.$ average) for 40 days and then frozen at $-20^{\circ} \mathrm{C}$ for subsequent measurement of ultimate $\mathrm{pH}$, shear force, cooking loss and purge loss.

\section{5. $\mathrm{pH}$ post-mortem and ultimate $\mathrm{pH}$}

The LL pH was measured at $24 \mathrm{~h}$ post-mortem $\left(\mathrm{pH}_{24} \mathrm{LL}\right)$ at the 12 th/ 13th rib site using a pH metre with temperature compensation (WP-80, TPS Pty Ltd., Brisbane, Australia) and a polypropylene spear-type gel electrode (Ionode IJ 44) calibrated using two pH buffers ( $\mathrm{pH} 4.01$ and pH 6.86), (Fowler, Schmidt, van de Ven, Wynn, \& Hopkins, 2015).

The ultimate $\mathrm{pH}$ of the $m$. semimembranosus (pHuSM) was measured after 40 days of ageing. Approximately $1 \mathrm{~g}$ of tissue was removed from each still frozen sample, and then homogenised at 19,000 rpm for 2 bursts of $15 \mathrm{~s}$ (Ystral homogeniser: Series X10/25, Ystral, Germany) in $50 \mathrm{~mL}$ Falcon tubes containing $6 \mathrm{~mL}$ of buffer solution (Dransfield, 
Etherington, \& Taylor, 1992). The samples were placed in a water bath at $20{ }^{\circ} \mathrm{C}$, and the $\mathrm{pH}$ measured using a $\mathrm{pH}$ metre (smartCHEM-CP, TPS Pty Ltd., Brisbane, Australia) with a polypropylene spear-type gel electrode (Ionode IJ 44) calibrated using two pH buffers ( $\mathrm{pH} 4.01$ and $\mathrm{pH}$ 6.86). Duplicate $\mathrm{pH}$ measures were recorded and a third was taken if 2 readings differed by more than \pm 0.03 .

\subsection{Instrumental colour measurement}

The cut surface of the LL was bloomed at ambient temperature for 30-40 min and fresh meat colour measured using a Minolta Chroma meter (Model CR-400) set on the CIE $L^{*}, a^{*}, b^{*}$ system (whereby $L^{*}$ measures relative lightness, $a^{*}$ relative redness and $b^{*}$ relative yellowness), and having an aperture size of $8 \mathrm{~mm}$, using the D65 illuminant and $10^{\circ}$ standard observer. This colorimeter was calibrated with a white tile $(\mathrm{Y}=92.8, \mathrm{x}=0.3160, \mathrm{y}=0.3323)$ and three replicate measurements were taken at different positions on the measured surface and their average recorded.

\subsection{Purge loss, moisture content, IMF and water activity}

Purge loss (PL) from each SM was calculated by weighing the muscle prior to vacuum packaging and reweighing after 40 days of ageing following drying of the muscle with paper towel when removed from the packaging.

The moisture content of all LL and AF muscles was measured by weighing samples prior to and post freeze drying at $-50{ }^{\circ} \mathrm{C}$ (ScanVac CoolSafeTM (LaboGene ApS., Lynge., Denmark) then recording the difference as a percentage. These same freeze-dried samples were stored at $-20{ }^{\circ} \mathrm{C}$ for determination of intramuscular fat (IMF). This entailed grinding the samples using a FOSS Knifetech ${ }^{\mathrm{TM}} 1095$ sample mill (FOSS Pacific, Unit 2, 112-118 Talavera Road, North Ryde, NSW, 2113) and then IMF determination using the FOSS Soxtec 2050 protocol as described by Hopkins et al. (2014).

The water activity (Aw) of LL sub-samples (Mean \pm s.d.; $1.0 \mathrm{~g} \pm$ $0.2 \mathrm{~g}$ ) aged for 5,12 and 40 days was measured (ROTRONIC probe type HC2-AW-(USB) attached to the HygroPalm23-AW). Aw values were recorded once stabilised and each sample was analysed in duplicate (Holman, Coombs, \& Hopkins, 2015).

\subsection{Cooking loss, shear force and sarcomere length}

Medial sections $(71.0 \pm 3.0 \mathrm{~g})$ were removed from each aged SM and weighed (pre-cook weight), vacuum packaged and then frozen at $-20{ }^{\circ} \mathrm{C}$ until analysis. Frozen samples (still vacuum packaged) were placed in a $71{ }^{\circ} \mathrm{C}$ water bath (Thermoline Scientific, Sydney, NSW, Australia) for $35 \mathrm{~min}$ in plastic bags, following which they were immediately cooled in cold tap water for $30 \mathrm{~min}$. Samples were then removed from bags, dried using paper towel and then reweighed (post-cook weight). The difference between post- and pre-cook weight was determined as a percentage of the pre-cook weight and defined as the cooking loss (CL). The cooked samples were then refrigerated overnight and used for shear force analysis. From each sample, six strips with a cross-sectional area of $1 \mathrm{~cm}^{2}$ were removed, parallel to the muscle fibre direction, with care to avoid connective tissue and fatty areas. A Lloyd texture analyser (Model LRX, Lloyd Instruments, Hampshire, UK) with a vee-shaped Warner-Bratzler cutting blade was then used to measure the peak force (Newtons) to cut each sample strip perpendicular to muscle fibres. The crosshead speed of the analyser was $200 \mathrm{~mm} / \mathrm{min}$ and shear force (SF) was calculated as the average of 6 subsamples (Hopkins, Toohey, Warner, Kerr, \& van de Ven, 2010).

Five thin subsamples parallel to muscle fibres were removed from each sample of frozen LL muscle (1 day aged) for the measurement of sarcomere length (SL). The method for the determination of SL was the same as previously described by Bouton, Fisher, Harris, Baxter (1973).

\subsection{Glycogen content}

Glycogen content was tested using approximately $1.0 \mathrm{~g}$ of tissue removed from each still frozen LL from the right side sample (kept at $-80^{\circ} \mathrm{C}$ ). This was added to individual $50 \mathrm{~mL}$ Falcon tubes containing $10 \mathrm{~mL}$ of ice-cold Milli-Q water which were then incubated in boiling water $\left(100{ }^{\circ} \mathrm{C}\right)$ for $5 \mathrm{~min}$ and then homogenised for two bursts $(22,000 \mathrm{rpm})$ of $15 \mathrm{~s}$ (Ystral homogeniser: Series X10/25, Ystral, Germany). Still in original Falcon tubes, individual samples were centrifuged (Model CPR, Beckman Instruments, CA, USA) at $3500 \mathrm{rpm}$ for 15 min. The supernatant was then compared against a glycogen standard using the colorimetric protocol detailed by the Glycogen Assay Kit (Sigma-Aldrich, MO, USA; Ref. MAK016) - technical bulletin (Sigma-Aldrich, 2015) and using a micro-plate reader (FLUOstar OPTIMA, BMG, Labtechnologies, Victoria, Australia) measuring at $570 \mathrm{~nm}$. Samples were tested as technical duplicates.

\subsection{Sensory}

The sensory design was modified from that described by Thompson et al. (2005). Ten (10) LL muscles per forage-type were cut into five slices per LL from the 5 day aged, giving a total of 250 steaks. These were labelled and then frozen at $-20^{\circ} \mathrm{C}$ until required for sensory testing. On the day of testing, frozen samples were thawed slowly in cooled boxes for $21 \mathrm{~h}$ at $1-2{ }^{\circ} \mathrm{C}$ before cooking. Samples were tested in 4 sessions with 2 sessions held per day and 16 people per session, resulting in a total of 64 untrained consumers. The sample allocation was based on having each LL tested by ten different panellists, and each panellist testing samples from each forage-type. For each session, eight (8) steaks were cooked for a set time on a Griddler Clam Grill (Cuisinart ${ }^{\mathrm{TM}}$ Griddler clam grill GR-4A) to reach an internal temperature of approximately $71{ }^{\circ} \mathrm{C}$ to achieve a medium degree of doneness prior to being rested for $2 \mathrm{~min}$; the steaks were cut in half (to produce 10 separate samples per $\mathrm{LL}$, and equating to a total of 500 samples from the forage-type); then served warm to 16 panellists. For the first three sessions each panellist was served at the start with a blank sample (samples from a commercial source) to familiarise them with the sensory protocol, followed by 8 experimental samples. For the fourth session just four panellists were served the blank sample, plus 8 experimental samples, and the other twelve panellists were served 2 blank samples followed by 7 experimental samples, giving a total of 500 experimental samples. Panellists were screened to include only individuals who ate red meat a minimum of once per week. Each panellist completed a questionnaire pertaining to their: age $(18-25,26-30,31-39,40-55,55+)$; sex (male or female); occupation; how many people normally live in their house (adults and children); frequency with which they consume red meat (daily, 4-5 times per week, 2-3 times per week, weekly, fortnightly, monthly, less often or never); attitude to red meat (I enjoy red meat, it is an important part of my diet, I like red meat well enough. It is a regular part of my diet, I do eat some red meat although, truthfully it would not worry me if I did not or I rarely/never eat red meat); preferred level of cooking or doneness (rare, medium or well done); and what income level best categorised their household? ( $<\$ 45,000$ per year, $\$ 45,000-\$ 80,000$ per year or $>\$ 80,000$ per year). After this samples were individually presented to panellists in a predetermined order. The score of each sample was captured on a single sheet, using four $100 \mathrm{~mm}$ line scales. These lines were anchored with the following words: tenderness (not tender to very tender), juiciness (not juicy to very juicy), liking of flavour (dislike extremely to like extremely) and overall liking (dislike extremely to like extremely) and panellists were asked to rate the quality of the sample (unsatisfactory, good everyday quality, better than everyday quality or premium quality). Panellists were offered a palette cleanser (water and crackers) before each sample was served. 


\subsection{Statistical analyses}

The carcass traits (HCW, DP, GR, FatC, EMA, EMD and EMW) and physical meat traits (pHuSM, $\mathrm{pH}_{24} \mathrm{LL}, L^{*}, a^{*}, b^{*}, \mathrm{Aw}, \mathrm{SF}, \mathrm{SL}, \mathrm{CL}, \mathrm{PL}, \mathrm{IMF}$, moisture and glycogen) were analysed using mixed model regression analyses, with forage-type, gender, and for some traits a covariate, fitted as fixed effects and plot as a random effect. For carcase traits, other than HCW and DP, HCW was included as a covariate. For the meat trait PL, the pHuSM was included as a covariate. For traits SL, moisture, Aw and colour parameters of the $\mathrm{LL}$, the $\mathrm{pH}_{24} \mathrm{LL}$ was included as a covariate; and for the SF, CL, and PL, the pHuSM was included as a covariate. For each trait, predicted means for each forage type when fed to a male, adjusted to the mean covariate value where appropriate, were compared by the Fishers protected least significant difference (LSD) at the 5\% level.

For sensory characteristics a linear mixed model was used to analyse tenderness, juiciness, flavour, overall liking and rating quality of each sample, to identify the factors influencing the response. The fixed effects in the model included forage-type, gender of animal, sex of panellists (female, male, unknown), age of panellist (18-25, 26-30, 31-39, 40$55,55+$ ), preferred degrees of doneness (PDD) (rare, medium, well done, unknown), income ( $<45,000,45,000-80,000,>80,000$, unknown) and red meat consumption frequency (RMFreq) (daily, 4-5 times, 2-3 times, weekly, fortnightly, unknown). Covariates in the model, fitted as fixed effects, included the order of sample testing by a panellist and the number of adults in a household minus 3, with household having unknown adults assigned zero (AdjAdults). Also fitted as covariates were quantitative versions of Age, PDD, Income and RMFreq (denoted by QAge, QPDD, QIncome and QRMFreq respectively). Each quantitative version here is first assigned the corresponding ordered factor level (ignoring the unknown level if present); then adjusted by subtracting the middle value; and finally assigning a value 0 to the unknowns (if present). Hence, for example, RMFreq, at ordered factor levels daily, 4-5 times, 2-3 times, weekly, fortnightly and unknown, are assigned $-2,-1,0,1,2$ and 0 respectively. The terms QAge, QPDD, QIncome and QRMFreq are included in the model before Age, PDD, Income and RMFreq to test if any significance associated with any of these four factors, if present, can be explained linearly. The purpose of including unknown's as 0 for the quantitative traits is to minimise their influence on the regression estimates for linear trends.

The random effects in the model were: plot (15 levels), panellist (64 levels), carcass (50 levels), slice within carcass (250 levels), date (2 levels), session (4 levels), order of tasting (8 levels), panellist's occupation ( 7 levels) and error. Each model was simplified by excluding non-significant $(P>0.05)$ fixed effect terms. Regression modelling analyses were performed using the asreml package (Butler, 2009) under $R$ (R Core Team, 2015).

\section{Results}

\subsection{Carcass characteristics}

The results for the carcass traits are given in Table 2. The forage-type influenced DP $(P<0.05)$ and GR tissue depth $(P<0.05)$. Lambs fed chicory + arrowleaf clover or lucerne had a higher DP than lambs fed the other forage-types with lambs fed bladder clover having the lowest dressing percentage. Hot carcase weight did not differ significantly with forage-type, however there was a gender effect with wether lambs producing heavier carcasses $(P<0.05: 3.06 \pm 1.39 \mathrm{~kg})$.

Lambs fed chicory + arrowleaf clover, lucerne or brassica had a higher GR tissue depth than lambs fed lucerne + phalaris or bladder clover when adjusted to a common hot carcass weight. Although there was no forage-type effect on subcutaneous fat depth there was a trend $(P=0.07)$ for lambs fed chicory + arrowleaf clover, lucerne or brassica to have more fat. There was no effect of forage-type on eye muscle area, eye muscle depth or eye muscle width when differences in carcass weight were accounted for, but there was a gender effect with wether lambs having a greater eye muscle width when adjusted for carcass weight $(P<0.05: 2.31 \pm 1.11 \mathrm{~mm})$.

\subsection{Meat quality characteristics}

Forage-type had an effect $(P<0.05)$ on $\mathrm{pH}_{24} \mathrm{LL}$ and glycogen content (Table 3). Lambs fed chicory + arrowleaf clover had the lowest $\mathrm{pH}_{24} \mathrm{LL}$, however this forage-type did not differ significantly from lucerne. A higher $\mathrm{pH}_{24} \mathrm{LL}$ was observed in lambs fed bladder clover, lucerne + phalaris and brassica without a difference between them. There was no effect of forage-type on the pHuSM however the values were higher than for $\mathrm{pH}_{24} \mathrm{LL}$.

The glycogen content of LL was higher when lambs grazed bladder clover, compared to lambs that grazed brassica, chicory + arrowleaf clover or lucerne, while the glycogen level of lambs that were fed lucerne + phalaris that did not differ significantly from the other forage-type (Table 3).

The fresh colour parameters, lightness $\left(L^{*}\right)$, redness $\left(a^{*}\right)$ and yellowness $\left(b^{*}\right)$ of the LL at $24 \mathrm{~h}$ post-mortem were not affected by forage-type when adjusted for pH effects (Table 3 ). There was no difference in Aw of the LL between forage-types for any of the three ageing times (5, 12 and 40 days). No effects of forage-type were found for SF of the SM, SL of the LL, CL, PL of the SM or moisture content of the LL and AF. IMF, for both muscle types, was not affected by forage-type grazed, however the IMF values for the AF muscle were lower than those of the LL.

Table 2

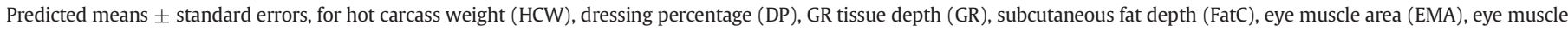
depth (EMD), eye muscle width (EMW) of lambs fed different forage types.

\begin{tabular}{|c|c|c|c|c|c|c|}
\hline \multirow[t]{2}{*}{ Traits } & \multicolumn{5}{|l|}{ Forage-types } & \multirow[t]{2}{*}{ LSD } \\
\hline & Bladder clover & Brassica & Chic/arrow ${ }^{\mathrm{a}}$ & Luc/phal ${ }^{\mathrm{b}}$ & Lucerne & \\
\hline HCW (kg) & $21.7 \pm 1.1$ & $23.5 \pm 1.3$ & $25.1 \pm 1.1$ & $22.1 \pm 1.2$ & $24.9 \pm 1.4$ & 3.6 \\
\hline DP $(\%)$ & $49.2 \pm 0.9 \mathrm{a}$ & $51.5 \pm 1.1 \mathrm{a}$ & $54.7 \pm 0.9 b$ & $51.3 \pm 1.1 \mathrm{a}$ & $54.7 \pm 1.1 b$ & 3.1 \\
\hline $\mathrm{GR}(\mathrm{mm})^{\mathrm{c}}$ & $9.0 \pm 0.9 \mathrm{a}$ & $12.7 \pm 1.0 \mathrm{~b}$ & $13.6 \pm 0.9 b$ & $9.9 \pm 1.0 \mathrm{a}$ & $13.5 \pm 1.0 \mathrm{~b}$ & 3.1 \\
\hline FatC $(\mathrm{mm})^{\mathrm{c}}$ & $2.7 \pm 0.5$ & $3.8 \pm 0.5$ & $3.6 \pm 0.4$ & $2.7 \pm 0.5$ & $3.8 \pm 0.5$ & 1.3 \\
\hline $\operatorname{EMA}\left(\mathrm{cm}^{2}\right)^{\mathrm{d}}$ & $17.9 \pm 0.7$ & $17.6 \pm 0.7$ & $17.9 \pm 0.8$ & $17.2 \pm 0.8$ & $18.1 \pm 0.7$ & 2.3 \\
\hline $\operatorname{EMD}(\mathrm{mm})^{\mathrm{d}}$ & $33.7 \pm 1.2$ & $33.2 \pm 1.3$ & $35.1 \pm 1.3$ & $31.9 \pm 1.3$ & $34.7 \pm 1.2$ & 3.9 \\
\hline EMW $(\mathrm{mm})^{\mathrm{d}}$ & $66.2 \pm 0.9$ & $65.7 \pm 0.9$ & $63.9 \pm 0.9$ & $66.6 \pm 0.9$ & $65.4 \pm 0.9$ & 2.9 \\
\hline
\end{tabular}

Means followed by different letters in rows differ $(P<0.05)$ based on an LSD means.

a Chic/arrow - chicory + arrowleaf clover.

b Luc/phal - lucerne + phalaris.

c Adjusted for HCW.

d For longissimus lumborum. 
Table 3

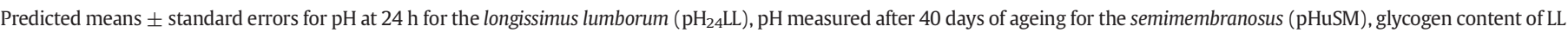

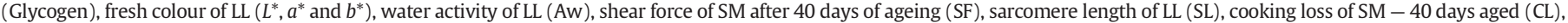

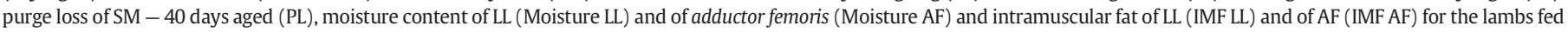
on different forages types.

\begin{tabular}{|c|c|c|c|c|c|c|}
\hline \multirow[t]{2}{*}{ Traits } & \multicolumn{5}{|l|}{ Forage-types } & \multirow[t]{2}{*}{ LSD } \\
\hline & Bladder clover & Brassica & Chic/arrow $^{\mathrm{a}}$ & Luc/phal ${ }^{\mathrm{b}}$ & Lucerne & \\
\hline $\mathrm{pH}_{24} \mathrm{LL}$ & $5.62 \pm 0.02 c$ & $5.61 \pm 0.02 b c$ & $5.57 \pm 0.02 a$ & $5.63 \pm 0.02 c$ & $5.59 \pm 0.02 \mathrm{ab}$ & 0.03 \\
\hline pHuSM & $5.70 \pm 0.02$ & $5.76 \pm 0.02$ & $5.71 \pm 0.02$ & $5.72 \pm 0.02$ & $5.71 \pm 0.01$ & 0.05 \\
\hline Glycogen (mmol/kg) & $110.4 \pm 6.6 b$ & $79.5 \pm 6.8 a$ & $88.7 \pm 6.2 a$ & $91.6 \pm 6.9 \mathrm{ab}$ & $85.9 \pm 6.9 a$ & 20.6 \\
\hline$L^{*}$ fresh colour & $38.0 \pm 0.5$ & $37.2 \pm 0.5$ & $38.9 \pm 0.5$ & $38.0 \pm 0.5$ & $38.5 \pm 0.5$ & 1.6 \\
\hline$a^{*}$ fresh colour ${ }^{c}$ & $15.5 \pm 0.3$ & $16.0 \pm 0.3$ & $15.8 \pm 0.3$ & $15.9 \pm 0.3$ & $15.2 \pm 0.3$ & 0.9 \\
\hline$b^{*}$ fresh colour ${ }^{\mathrm{c}}$ & $1.2 \pm 0.2$ & $1.1 \pm 0.1$ & $1.5 \pm 0.2$ & $1.6 \pm 0.1$ & $1.2 \pm 0.1$ & 0.5 \\
\hline Aw 5 days aged & $0.957 \pm 0.003$ & $0.954 \pm 0.003$ & $0.956 \pm 0.003$ & $0.960 \pm 0.003$ & $0.958 \pm 0.003$ & 0.009 \\
\hline Aw 12 days aged & $0.963 \pm 0.002$ & $0.960 \pm 0.002$ & $0.961 \pm 0.002$ & $0.963 \pm 0.002$ & $0.961 \pm 0.002$ & 0.007 \\
\hline Aw 40 days aged & $0.957 \pm 0.003$ & $0.958 \pm 0.003$ & $0.961 \pm 0.003$ & $0.961 \pm 0.003$ & $0.959 \pm 0.003$ & 0.009 \\
\hline $\mathrm{SF}(\mathrm{N})$ & $34.6 \pm 1.3$ & $36.2 \pm 1.2$ & $34.3 \pm 1.1$ & $36.3 \pm 1.2$ & $37.4 \pm 1.3$ & 3.8 \\
\hline $\mathrm{SL}(\mu \mathrm{m})$ & $1.7 \pm 0.1$ & $1.8 \pm 0.1$ & $1.9 \pm 0.1$ & $1.7 \pm 0.1$ & $1.8 \pm 0.01$ & 0.1 \\
\hline $\mathrm{CL}(\%)$ & $20.5 \pm 0.3$ & $20.4 \pm 0.4$ & $20.0 \pm 0.4$ & $21.4 \pm 0.4$ & $21.2 \pm 0.4$ & 1.2 \\
\hline PL (\%) & $8.1 \pm 0.8$ & $6.0 \pm 0.9$ & $6.7 \pm 0.8$ & $8.2 \pm 0.8$ & $5.9 \pm 0.9$ & 2.5 \\
\hline Moisture LL (\%) & $62.4 \pm 0.6$ & $62.9 \pm 0.6$ & $62.6 \pm 0.5$ & $62.6 \pm 0.5$ & $63.2 \pm 0.5$ & 1.7 \\
\hline Moisture AF (\%) & $63.5 \pm 0.2$ & $63.3 \pm 0.3$ & $63.8 \pm 0.3$ & $64.1 \pm 0.3$ & $63.5 \pm 0.3$ & 0.8 \\
\hline $\operatorname{IMF}$ AF (\%) & $1.5 \pm 0.2$ & $1.5 \pm 0.1$ & $1.6 \pm 0.1$ & $1.4 \pm 0.2$ & $1.4 \pm 0.2$ & 0.3 \\
\hline IMF LL (\%) & $1.7 \pm 0.1$ & $2.1 \pm 0.2$ & $2.3 \pm 0.2$ & $1.7 \pm 0.2$ & $1.9 \pm 0.1$ & 0.6 \\
\hline
\end{tabular}

Means followed by different letters in rows differ $(P<0.05)$ based on an LSD.

a Chic/arrow - chicory + arrowleaf clover.

b Luc/phal - lucerne + phalaris.

c Adjusted for $\mathrm{LLPH}_{24}$.

\subsection{Sensory}

There were no significant effects of forage-type on the sensory traits (Table 4). The simple means for tenderness, juiciness, liking flavour, overall liking and rating quality of the samples are given in Table 4. Of the terms considered in the model that categorise the panellists, only age of panellist, income of panellist, and number of adults living in a household (or a subset of these) significantly influenced the sensory responses, though not for all traits. These are summarised briefly in the following two paragraphs.

For tenderness, the significant effects $(P<0.05)$ were AdjAdults, QIncome and Age, with the AdjAdults and QIncome terms only marginally significant. The tenderness score was estimated to decrease $-5.4 \pm 2.7$ units with each increasing income category; increase $4.8 \pm 2.4$ units with each extra adult in the household; and was significantly less, $22.7 \pm 5.9$ units for panellists from the youngest age category (18-25) compared with the other ages groups. The other age groups did not differ significantly. Note that these differences are when the other factors are fixed.

For juiciness and overall liking only the QAge score of the panellist had a significant $(P<0.05)$ influence, with juiciness score increasing $3.5 \pm 1.3$ units and overall liking by $2.0 \pm 1.0$ units for each step increase in age category of the panellist. Significant non-linear Age and Income effects were observed for the flavour trait. There were no effects on the rating of Quality by any of the variables categorising panellists.

Table 4

Means and standard error for sensory traits: Tenderness, Juiciness, liking of Flavour, overall liking (Overall) and rating quality of the sample (Quality) of the longissimus lumborum (LL) muscle from lambs feed on different forages types.

\begin{tabular}{llllll}
\hline \multirow{2}{*}{ Means } & \multicolumn{3}{l}{ Sensory attributes ${ }^{\mathrm{a}}$} \\
\cline { 2 - 6 } & Tenderness & Juiciness & Flavour & Overall & Quality $^{\mathrm{b}}$ \\
\hline Mean & 64.3 & 63.1 & 65.7 & 64.9 & 2.6 \\
Standard error & 2.3 & 2.2 & 1.5 & 1.6 & 0.1 \\
\hline
\end{tabular}

a $100 \mathrm{~mm}$ line scales.

b 1 to 4 .

\section{Discussion}

\subsection{Carcass characteristics}

Lambs fed chicory + arrowleaf clover or lucerne produced fatter carcasses than the lambs fed other forage-types. This reflects the comparably higher content of ME and $\mathrm{CP}$ in these forages (Table 1), with the exception being lambs fed brassica. These animals were of similar fatness based on the GR measure, yet the brassica forage had lower average values for these nutrition traits and in fact there was a marked decline in nutritive value in December, so why lambs offered this forage had a similar GR fat depth to lambs grazed the higher quality pastures is unclear. Barry (1998) found a higher concentration of readily fermentable carbohydrates (sugar and pectin) and lower concentrations of structural carbohydrates (cellulose and hemicellulose) in chicory compared to perennial ryegrass and red clover. Similarly, Fraser and Rowarth (1996) reported chicory to have a higher CP content and digestibility than plantain, white clover, lotus and ryegrass, and this led to a high GR in grazing lambs. However, this study associated the high GR with the greater carcass weight of the lambs, something that could have been clarified by using carcass weight as a covariate. It is noteworthy in the current study that lambs fed the bladder clover produced leaner carcasses, yet the ME of this forage was higher and with lower quality loss than the brassica over the experimental period. Hopkins et al. (1995b) evaluated lambs fed chicory and lucerne and reported no difference between the treatments for HCW or fat levels (GR and Fat C) with the latter measures adjusted for carcass weight. It should be noted though that the Hopkins et al. (1995b) study did not employ replication at the treatment level so there is reduced certainty about these results. In the current study there was a weak trend $(P=0.12)$ for a higher HCW for lambs fed chicory + arrowleaf clover or lucerne, but there were no significant differences across forage-types which may well reflect the treatment group sizes (i.e. lack of statistical power). HCW is an important output from lamb production systems and along with fat score impacts on the price received by producers. As a consequence, the leaner carcasses of lambs fed bladder clover and lucerne + phalaris could demand a premium, given the lower levels of fat, however this may just reflect a lower growth rate (McGrath et al., 2015). 
Dressing percentage (DP) is an important carcass characteristic (Hopkins, 1992) as it impacts on HCW relative to pre-slaughter weight, and it can be influenced, in turn, by several factors such as breed, live weight, carcass fat level and time off water (Turner, Belesky, Cassida \& Zerby, 2014). The DP followed the same pattern as for GR, with higher values for the lambs fed chicory + arrowleaf clover or lucerne. The exception was lambs fed brassica as the GR level was similar to those fed chicory + arrowleaf clover or lucerne, yet the DP was significantly less. This may indicate a higher gut fill in the brassica fed lambs, consistent with the reduced ME of this forage. There is evidence that lambs fed on brassicas will be fatter than those finished on grass (Scales, 1993), a finding supported by the work of Hopkins et al. (1995a). In that latter study, again without replication of the treatments, brassica fed lambs had a higher DP than lambs finished on pasture. In contrast, the current study lambs fed lucerne + phalaris produced leaner carcasses than all other forage types except for those fed bladder clover, likely due to lower $\mathrm{CP}$ and ME and higher NDF content in the diet compared to other treatments.

\subsection{Meat quality characteristics}

Lambs fed bladder clover or lucerne + phalaris had the highest $\mathrm{pH}$ in LL muscle at $24 \mathrm{~h}$ post-mortem, yet they also had the highest glycogen content. This was unexpected as these forages did not have the highest energy levels compared to other forage-types investigated, and basal levels of glycogen have been found responsive to dietary energy levels (Pethick \& Rowe, 1996). However, Daly, Gardner, Ferguson, Thompson (2006), reported a curvilinear relationship between $\mathrm{pH}$ and muscle glycogen levels such that after $60 \mathrm{mmol} / \mathrm{kg}$ the $\mathrm{pH}$ increased. The absolute levels for glycogen content in this study were higher than those reported by Lowe, Peachey, Devine (2002) for lambs grazing ryegrass and clover pasture that had $42.5 \mathrm{mmol} / \mathrm{kg}$ of glycogen residual in meat and that of Daly et al. (2006) at $45.5 \mathrm{mmol} / \mathrm{kg}$ suggesting the forages provided to the lambs in the current study were all of high energetic value. A number of factors influence the accumulation of glycogen in muscle such as pre-slaughter exercise (Lowe et al., 2002), and energy intake (Pethick \& Rowe, 1996). Despite this it should be noted that the differences in $\mathrm{pH}$ between groups were not large and the mean $\mathrm{pH}$ was below the acceptable threshold (5.8) in terms of microbiological stability (Egan \& Shay, 1988) and the Aw results support this observation as there were no differences between forage types. Overall, the glycogen and $\mathrm{pH}$ levels suggest the lambs were subjected to low levels of pre-slaughter stress (Gardner, Kennedy, Milton, \& Pethick, 1999).

There was no impact of forage-type on meat colour traits independent of $\mathrm{pH}$. This concurs with a previous study that compared chicory and lucerne (Hopkins et al., 1995b), however in a comparison of brassica and irrigated pasture fed lambs Hopkins et al. (1995a) did find lighter LL and SM muscles in the lambs grazing brassica, even after accounting for differences in carcase weight and GR fat level. In the current study lambs fed bladder clover and lucerne + phalaris were leaner, yet this did not impact on the meat colour traits in contrast to the findings of Hopkins et al. (1995a). Meat colour is an important factor impacting on consumer purchase, constituting the main criterion for the choice of meat. Values for lightness $\left(L^{*}\right)$ below 34 and redness $\left(a^{*}\right)$ below 9.5 are considered dark and unacceptable to average consumers as reported by Khliji, van de Ven, Lamb, Lanza, and Hopkins (2010) and thus the mean values for lightness and redness in the current study can be considered acceptable.

There was no effect of forage-type on the SF of the SM muscle and the absolute values were lower than those reported by Hopkins et al. (1995a), probably reflecting the long ageing period applied in the current study. In fact, the observed levels were lower than the conservative SF threshold suggested by Hopkins, Hegarty, Walker, Pethick (2006) and were within the range indicative of good eating quality as suggested by Hopkins et al. (2006). The lack of difference between treatment groups for SL and CL is consistent with the null effect on SF. The levels of PL across forage-types were higher than previously reported for the same muscle, but under shorter ageing periods ( 5 days aged) (Fowler et al., 2015) suggesting a significant loss in weight for customers of long aged vacuum packed lamb.

IMF is a significant trait for lamb eating quality (Hopkins et al., 2006) so, it was notable there was no effect of forage-type on IMF levels in the current study, however the levels in the AF and LL were low when compared to what is considered an optimal target. For lamb, a recent target of $4 \%$ IMF has been suggested by Pannier et al. (2014). There is to our knowledge no published data on the IMF level of the AF, for lamb, but previous studies have shown that the closely related SM will have lower IMF levels than the LL (Anderson, Pethick, \& Gardner, 2015).

\subsection{Sensory}

In general, the consumer evaluation undertaken in this study showed no difference between the treatments for sensory attributes and this is a positive result as Australian producers have more options when selecting forages for finishing lambs without the risk of producing unacceptable meat. Hopkins et al. (1995a) found a significantly stronger flavour and aroma of the LL from lambs fed brassica compared to those fed irrigated pasture, and in other studies the meat of lambs grazed on brassica was considered less acceptable, having an oily, nutty and musty flavour (Scales, 1993). This could be a result of the brassica producing volatile sulphur-containing compounds which change the meat flavour of lamb meat as a result of thermal reactions under cooking (Hurrel, 1982). However, in the current study a stronger flavour was not perceived by the consumer panel for any forage-type evaluated and this may be due to the duration of the feeding period (49 days) or stage of plant growth not having been sufficient for the necessary accumulation of flavour and aroma compounds. Additionally the samples were presented to panellists without subcutaneous fat a known source of flavour and aroma compounds.

Studies indicate that the palatability as a function of tenderness, juiciness, and flavour plays an important role in the acceptance of meat by consumers (Thompson et al., 2005) and fat content has a key role to ensuring palatability (Hocquette et al., 2010). Despite the lower IMF levels found in the current study, consumer perceived eating quality was comparable to that reported by Hopkins et al. (2006).

\section{Conclusion}

For the production of heavy lean lambs, the newer forage-type bladder clover or the common forage-type lucerne + phalaris are recommended from the selection of forages-types examined in this study, although this requires further confirmation. The lambs fed on chicory + arrowleaf clover produced loin meat with the lowest $\mathrm{pH}$ and moderate glycogen levels in the same way as lucerne, which could be advantageous under stressful conditions. In general all forage-types achieved good results in terms of their effect on carcass characteristics, meat quality and sensory attributes and thus are all valid options to finish lambs.

\section{Acknowledgements}

The first author acknowledges the NSW Department of Primary Industries (NSW, DPI), Centre for Red Meat \& Sheep Development Cowra, Australia for hosting her as a PhD student from Brazil. The first author is thankful to CAPES (Coordination for the Improvement of Higher Education Personnel) for scholarship funding in Brazil (15/2014) and Australia (3337/15-4). The authors are grateful for the technical support of Ms. Tracy Lamb, Ms. Jordan Hoban and Mr. Matthew Kerr (NSW DPI); Mr. Isaac James and Mr. Timothy MorleySattler (CSU) and the cooperation of the abattoir. The financial support of Meat and Livestock Australia (MLA) for the grazing experiment is gratefully acknowledged as is the work of Dr. Graeme Sandral (NSW 
DPI) in the establishment of the plots and Dr. Neil Coombes (NSW DPI) in the allocation of sensory samples to panellists and sessions.

\section{References}

Anderson, F., Pethick, D. W., \& Gardner, G. E. (2015). The correlation of intramuscular fat content between muscles of the lamb carcass and the use of computed tomography to predict intramuscular fat percentage in lambs. Animal, 9, 1239-1249.

Anonymous (2005). Handbook of Australian meat (7th ed.). Brisbane, Australia: AUS MEAT Limited.

Aurousseau, B., Bauchart, D., Galot, A. L., Prache, S., Micol, D., \& Priolo, A. (2007). Indoor fattening of lambs raised on pasture: 2. Influence of stall finishing duration on triglyceride and phospholipid fatty acids in the longissimus thoracis muscle. Meat Science, 76, 417-427.

Barry, T. N. (1998). The feeding value of Chicoty (Cichorium intybus) for ruminat livestock. Journal of Agricultural Science, 131, 251-257.

Blackburn, H. D., Snowder, G. D., \& Glimp, H. (1991). Simulation of lean lamb production systems. Journal of Animal Science, 69, 115-124.

Bouton, P. E., Fisher, A. L., Harris, P. V., \& Baxter, R. I. (1973). A comparison of the effects of some post-slaughter treatments on the tenderness of beef. Journal of Food Technology, 8, 39-49.

Brown, C. (1990). An integrated herbage system for Southland and South Otago. Proceedings of the New Zealand Grassland Association. 52. (pp. 119-122).

Butler, D. (2009). asreml: asreml() fits the linear mixed model. $R$ package version 3.0 (www.vsni.co.uk)

Cook, C. W. (1964). Symposium on nutrition of forages and pastures: Collecting forage samples representative of ingested material of grazing animals for nutritional studies. Journal of Animal Science, 23, 265-270.

CSIRO (2007). Nutrient requirements of domesticated ruminants. Melbourne, Australia: CSIRO Publishing.

Daly, B. L., Gardner, G. E., Ferguson, D. M., \& Thompson, J. M. (2006). The effect of time of feed prior to slaughter on muscle glycogen metabolism and rate of $\mathrm{pH}$ decline in three different muscles of stimulated and non-simulated sheep carcasses. Australian Journal of Experimental Agriculture, 57, 1229-1235.

Dransfield, E., Etherington, D. J., \& Taylor, M. A. J. (1992). Modelling post-mortem tenderisation: 11. Enzyme changes during storage of electrically stimulated and non-stimulated beef. Meat Science, 31, 75-84.

Egan, A. F., \& Shay, B. J. (1988). Long-term storage of chilled fresh meats. Proceedings of the international meat science and technology congress. 34. (pp. 476).

Fowler, S. M., Schmidt, H., van de Ven, R., Wynn, P., \& Hopkins, D. L. (2015). Predicting meat quality traits of ovine $\mathrm{m}$. semimembranosus, both fresh and following freezing and thawing, using a hand held Raman spectroscopic device. Meat Science, 108 $138-144$.

Fraser T., J., \& Rowarth, J. (1996). Legumes, herbs or grass for lamb performance? Proceedings of the New Zealand grassland association. 58. (pp. 49-52).

Gardner, G. E., Kennedy, L., Milton, J. T. B., \& Pethick, D. W. (1999). Glycogen metabolism and ultimate $\mathrm{pH}$ of muscle in merino, first-cross, and second-cross wether lambs as affected by stress before slaughter. Australian Journal of Agricultural Research, 50, $175-181$.

Grunert, K. G., Bredahl, L. \& Brunsø, K. (2004). Consumer perception of meat quality and implications for product development in the meat sector-A review. Meat Science, 66 , 259-272.

Hocquette, J. F., Gondret, F., Baéza, E., Médale, F., Jurie, C., \& Pethick, D. W. (2010) Intramuscular fat content in meat-producing animals: Development, genetic and nutritional control, and identification of putative markers. Animal, 4, 303-319.

Holman, B. W. B., Coombs, C. E. O., \& Hopkins, D. L. (2015). The effect of long-term chilled ageing duration on lamb meat water activity. Proceedings of international congress of meat science and technology.. 61. (pp. 1-4).

Hopkins, D. L., Gilbert, K. D., Pirlot, K. L., \& Roberts, A. H. K. (1992). Elliottdale and crossbred lambs - Growth rate, wool production, fat depth, saleable meat yield, carcass composition and muscle content of selected cuts. Australian Journal of Experimenta Agriculture, 32, 429-434

Hopkins, D. L. (1992). Factors affecting the dressing percentage of lambs. Small Ruminan Research, 6, 323-328.

Hopkins, D. L., Beattie, A. S., \& Pirlot, K. L. (1995a). Meat quality, carcass fatness, and growth of short scrotum lambs grazing either forage rape or irrigated perennial pasture. Australian Journal of Experimental Agriculture, 35, 453-459.

Hopkins, D. L. Holst, P. J., Hall, D. G., \& Atkinson, W. R. (1995b). Carcass and meat quality of second-cross cryptorchid lambs grazed on chicory (Cichorium intybus) or lucerne (Medicago sativa). Australian Journal of Experimental Agriculture, 35, 693-697.

Hopkins, D. L., Hegarty, R. S., Walker, P. J., \& Pethick, D. W. (2006). Relationship between animal age, intramuscular fat, cooking loss, $\mathrm{pH}$, shear force and eating quality of aged meat from sheep. Australian Journal of Experimental Agriculture, 46, 879-884.

Hopkins, D. L., Toohey, E. S., Warner, R. D., Kerr, M. J., \& van de Ven, R. (2010). Measuring the shear force of lamb meat cooked from frozen samples: Comparison of two laboratories. Animal Production Science, 50, 382-385.
Hopkins, D. L., Clayton, E. H., Lamb, T. A., van de Ven, R. J., Refshauge, G., Kerr, M. J., ... Ponnampalam, E. N. (2014). The impact of supplementing lambs with algae on growth, meat traits and oxidative status. Meat Science, 98, 135-141.

Howes, N. L., Bekhit, A. E. A., Burritt, D. J., \& Campbell, A. W. (2015). Opportunities and implications of pasture-based lamb fattening to enhance the long-chain fatty acid composition in meat. Comprehensive Reviews in Food Science and Food Safety, 14, 22-36.

Hurrel, R. F. (1982). Maillard reaction in flavour. In I. D. Morton, \& A. J. Macleod (Eds.), Food flavours, part A, introduction. Elsevier Scientific: Netherland.

Jiang, H., Wang, Z., Ma, Y., Qu, Y., Lu, X., Guo, H., \& Luo, H. (2015). Effect of dietary lycopene supplementation on growth performance, meat quality, fatty acid profile and meat lipid oxidation in lambs in summer conditions. Small Ruminant Research, 131, 99-106.

Khliji, S., van de Ven, R., Lamb, T. A., Lanza, M., \& Hopkins, D. L. (2010). Relationship between consumer ranking of lamb colour and objective measures of colour. Meat Science, 85, 224-229.

Kim, Y. H. B., Stuart, A., Rosenvold, K., \& Maclennan, G. (2013). Effect of forage and retail packaging types on meat quality of long-term chilled lamb loins. Journal of Animal Science, 91, 5998-6007.

Lowe, T. E., Peachey, B. M., \& Devine, C. E. (2002). The effect of nutritional supplements on growth rate, stress responsiveness, muscle glycogen and meat tenderness in pastoral lambs. Meat Science, 62, 391-397.

McGrath, S., Sandral, G., \& Friend, M. (2015). Lamb growth rates on pasture: Assessing options for finishing lambs in spring. Proceedings of Australian Society of Agronomy Conference. 17. (pp. 1-4).

Nardone, A., Ronchi, B., Lacetera, N., Ranieri, M. S., \& Bernabucci, U. (2010). Effects of climate changes on animal production and sustainability of livestock systems. Livestock Science, 130, 57-69.

Packer, E. L., Clayton, E. H., \& Cusack, P. M. V. (2011). Rumen fermentation and liveweight gain in beef cattle treated with monensin and grazing lush forage. Australian Veterinary Journal, 89, 338-345.

Pannier, L., Gardner, G. E., Pearce, K. L., McDonagh, M., Ball, A. J., Jacob, R. H., \& Pethick, D. W. (2014). Associations of sire estimated breeding values and objective meat quality measurements with sensory scores in Australian lamb. Meat Science, 96, 1076-1087.

Park, R. J., Spurway, R. A \& Wheeler J. L. (1972). Flavour differences in meat from sheep grazed on pasture or winter forage crops. Journal of Agricultural Science, 78, 53-56.

Pethick, D. W., \& Rowe, J. B. (1996). The effect of nutrition and exercise in carcass parameters and the level of glycogen in skeletal muscle of merino sheep. Australian Journal of Agricultural Research, 47, 525-537.

Ponnampalam, E. N., Warner, R. D., Kitessa, S., McDonagh, M. B., Pethick, D. W., Allen, D., \& Hopkins, D. L. (2010). Influence of finishing systems and sampling site on fatty acid composition and retail shelf-life of lamb. Animal Production Science, 50, 775-781.

Ponnampalam, E. N., Butler, K. L., Pearce, K. M., Mortimer, S. I., Pethick, D. W., Ball, A. J., \& Hopkins, D. L. (2014). Sources of variation of health claimable long chain omega-3 fatty acids in meat from Australian lamb slaughtered at similar weights. Meat Science, 96, 1095-1103.

Core Team, R. (2015). R: A language and environment for statistical computing. Vienna, Austria: R Foundation for Statistical Computing (Retrieved from http://www. Rproject.org/).

Scales, G. H. (1993). Carcass fatness in lambs grazing various forages at different rates of liveweight gain. New Zealand Journal of Agricultural Research, 36, 243-251.

Sigma-Aldrich (2015). Glycogen assay kit, technical bulletin MAK016. Sigma-Aldrich Co. LLC. Retrieved from (www.sigmaaldrich.com/content/dam/sigmaaldrich/docs/ Sigma/Bulletin/1/mak016bul.pdf).

Thompson, J. M., Gee, A., Hopkins, D. L., Pethick, D. W., Baud, S. R., \& O'Halloran, W. J. (2005). Development of a sensory protocol for testing palatability of sheep meats. Australian Journal of Experimental Agriculture, 45, 469-476.

Toohey, E. S., van de Ven, R., Thompson, J. M., Geesink, G. H., \& Hopkins, D. L. (2013). SmartStretch ${ }^{\mathrm{TM}}$ Technology. III. The impact of medium voltage stimulation and SmartStretch ${ }^{\mathrm{TM}}$ Technology on sheep topside ( $m$. semimembranosus) meat quality traits under commercial processing conditions. Meat Science, 93, 187-193.

Turner, K. E., Belesky, D. P., Cassida K., A., \& Zerby, H. N. (2014). Carcass merit and meat quality in Suffolk lambs, Katahdin lambs, and meat-goat kids finished on a grasslegume pasture with and without supplementation. Meat Science, 98, 211-219.

Winichayakul, S., Cookson, R., Scott, R., Zhou, J., Zou, X., Roldan, M., ... Roberts, N. (2008). Delivery of grasses with high levels of unsaturated, protected fatty acids. Proceedings of the New Zealand Grassland Association.. 70. (pp. 211-216).

Wood, J. D., Richardson, R. I., Nute, G. R., Fisher, A. V., Campo, M. M., Kasapidou, E., ... Enser, M. (2004). Effects of fatty acids on meat quality: A review. Meat Science, 66, 21-32.

Woodward, B. W. \& Fernández, M. I. (1999). Comparison of conventional and organic beef production systems II. Carcass characteristics. Livestock Production Science, 61, 225-231.

Young, O. A., Cruickshank, G. J., MacLean, K. S., \& Muir, P. D. (1994). Quality of meat from lambs grazed on seven pasture species in Hawkes Bay. New Zealand Journal of Agricultural Research, 37, 177-186. 